\title{
Reconstruction of Chinese Media and Audience Relationship
}

\author{
Min Wang \\ Guizhou Minzu University, Guiyang, China \\ Email:wx19999@outlook.com
}

How to cite this paper: Wang, M. (2020). Reconstruction of Chinese Media and $\mathrm{Au}$ dience Relationship. Open Journal of Social Sciences, 8, 293-299.

https://doi.org/10.4236/jss.2020.811027

Received: November 2, 2020

Accepted: November 24, 2020

Published: November 27, 2020

Copyright $\odot 2020$ by author(s) and Scientific Research Publishing Inc. This work is licensed under the Creative Commons Attribution International License (CC BY 4.0).

http://creativecommons.org/licenses/by/4.0/

\section{(c) (i) Open Acces}

\begin{abstract}
With the advancement of mobile internet technology and new media technology, China has entered the era of media convergence, and the relationship between audiences and media is also quietly changing. Chinese media reconstructed their relationship with audiences by innovative ways of new media technology. Through combing and researching a large number of practical cases, the article has sorted out how the Chinese media can realize the emotional interaction and relationship reconstruction between the media and the audience through the reform and innovation of expression forms, narrative methods, and communication channels.
\end{abstract}

\section{Keywords}

Media Convergence Era, Audience Relationship, Reconstruction

\section{Introduction}

With the advancement of mobile internet technology and new media technology in China, the old and new media are showing the development characteristics of mutual penetration, collision and mutual promotion. Based on brand-new communication concepts and mobile internet technology, China's traditional media strives to adjust their attitudes, actively seek new ways of media integration, and achieve the goal of transforming to a new mainstream media by building a new platform for content production and new mobile terminals. In this context, Chinese news reports have begun to break through the original traditional forms of expression, gradually getting rid of formulaic and high-profile expressions, turning to technology-supported creation of new platforms, trying to subvert the traditional expression structure, and trying to use personalized contents and services of the company establish new communication and interac- 
tive relationships with the audience.

\section{Innovation of the Subject}

In the context of media convergence, hosts and reporters began to explore new human expressions as the main body of news dissemination. In the past, traditional news theories required the subject of news expression to dilute their emotions as much as possible and to objectively state the facts ( $\mathrm{Li}, 2020)$. However, in the era of media convergence, if traditional media does not change its posture and innovate in expressions, it will most likely be ignored or even forgotten by the audience. Therefore, China's news dissemination subjects try their best to meet the needs of the society during the media transformation stage, give full play to their strengths and advantages in the field of professional content production, and use personalized and humanized expressions to establish new relationships or rules of communication with the audience, and achieve the share of news meaning and emotional communication.

From the perspective of the content of expression, the subject of expression attaches importance to incorporating "relational information" in the reporting process. Different from facts and other content information, relationship information refers to the behavioral hints of the communicator through language, tone, demeanor, and rhythm. The receiver, through the process of decoding, transforms the relationship information into his own emotions and ideas through meaning construction, and gains the understanding of the relationship with the communicator (Tian \& Zhang, 2017). The main body of news dissemination considering in-depth about the incorporation of relationship information in the report, can not only convey the emotional connotation behind the news and give the information more value, but also can strengthen the relationship between the two parties in the subtle way to make the receiver understand.

At the end of January 2017, China Central Television reported on the trial operation of the country's first sky bike lane-the Yunding Road bike expressway in Xiamen, Fujian Province, using mobile live broadcast. The reporter made full use of spoken language and body language to show the audience the cycling scenery and thoughtful design on the bicycle lane, and also shared his experience and inner feelings during cycling with the majority of netizens. In the report, the on-camera reporter not only guides the audience to observe and experience, but also enriches the relationship information of the entire news event through their own control of the on-site rhythm, audience interaction and emotional expression, so that the news authentically realizes an "equal dialogue" form.

For another example, China Central Television launched a short video column "Anchor Talking News" on July 29, 2019. Compared with the wording and rigorous language in "CCTV News", the diction of the anchors in "Anchor Talking News" is more diversified, more grounded, and more lively, such as Ouyang Xiadan's "mustard" and "autocratic incurable diseases"; Haixia's "hehe"; Gangqiang's "niu" and "beauty". The anchors are lively and agile, and the occa- 
sional slightly playful way of expression not only makes their media images more diverse, more humane and friendly, but also better adapts to the audience's habits in the context of new media.

\section{Innovation of News Narrative Forms}

With the development of China's mobile Internet technology, the emergence of mobile terminal technologies such as mobile phones, computers, and wearable devices has provided new technical support for audiences to express themselves, share information, and socialize. Faced with the advantages of new media breaking through the limitations of time and space, the traditional media's unidirectional linear news dissemination method has been impacted and cannot meet the diverse needs of audiences. In the ecological environment of the development of financial media, the application of technological changes in news dissemination has brought new reporting forms to Chinese media, and guided the audience to finish the process of "decoding" with "service thinking" (Qi et al., 2020).

\subsection{Non-Linear Storytelling Narrative Structure Weakens the Sense of Distance in Cognitive State}

No matter how the presentation of news text changes, telling good stories is still the logic of audience thinking in the era of Chinese media convergence. As the content market tends to be "saturated", traditional media screens out the most meaningful information from complex news facts and raw data, and composes it into a structured, easy-to-understand and memorable news narrative, which becomes the key to shortening the emotional distance between the media and the public. Taking into account the user's communication habits and reading preferences, news reports in the era of media convergence have changed the past chaotic information dissemination mode, telling good stories to the audience in a non-linear form.

The report "The Network of Betrayers" launched by the National Public Broadcasting Corporation documentary channel can be regarded as a model of media news reporting. The work used visualization to display the complicated interpersonal relationships of Headley, who was the mastermind of the 2008 terrorist attack in Mumbai. Relying on new media technology, the report reorganized the news materials in the documentary, integrated diversified news elements such as interactive pictures, video, and audio, and presented it to the audience in a multiform storytelling narrative. Viewers can determine the order, scope, speed and form of viewing content by clicking, dragging, and pulling. They can quickly clarify the complicated relationships in the event while receiving the audio-visual content, thereby experiencing efficient and logical reading pleasure. Although many people are not optimistic about this mode of news reporting, its unique narrative mode still provides new ideas for the digital transformation of news reporting. 
Chinese media have made many attempts to innovate narrative methods by using new media technology. For example, in 2016, in the context of Chinese anti-corruption society, Tencent News' column "Factualism” launched a query database H5 "Hello Disciplinary Committee, Nice Work-Summary of Cases of Officials Dismissed in China since the $18^{\text {th }}$ National People's Congress", clicking the page that allows you to inquire about the officials' information that have been publicly notified by the government. In addition to personal data, statistics on the cause of the crime and comparison of the provinces can be provided. Many news with the structure are not like traditional news, which uses linear time as the clues of the "inverted pyramid", but pay more attention to the simultaneity of information. Therefore, they carry rich content, large amounts of data and comprehensive cases, but without orientation with specific conclusions. Users can retrieve personalized information according to their needs, realizing a "thousand people, thousand faces" form of communication.

\subsection{Full Sensory Narration Enhances the Sense of Substitution in Interpersonal Interaction}

Generally, traditional media often use an omniscient perspective to narrate when reporting. Although it is easy for people to understand and grasp the overall context of the event, the closed narrative system often makes the audience "a member of many onlookers" (He, 2020). In a personalized communication environment, the meaning of mobile scenes is greatly enhanced. With the support of real-world experience technology, audiences can actively participate in the entire process of news events, separated from the perspective of bystanders, and even get multi-sensory information feedback such as tactile, visual, and auditory in the experience. $\mathrm{H} 5, \mathrm{VR}$, interactive experience, positioning system etc., which suggest that Chinese traditional media news narrative is gradually transforming into a form based on big data technology to establish precise interactive connections with users. For example, the H5 "Long Interactive Comic Strip-Tianqu: The 36 Years of Drinking Water Repairing Canal by Huang Dafa in the Old Village of Zunyi" released by Thepapercn in April 2017, using water as the main line, and drop-down long comics, progressive animation, 360-degree panoramic photos, atlas, audio, video, interactive experience, and other forms of expression, which has shown a panoramic view of Huang Dafa's story of leading the old generation to repair canals and get rid of poverty and drive the new generation to get rich. Netizens have read, given a like, forwarded it, commented "can't be moved", "true, ordinary and great"... This news report not only won unanimous praise from netizens, but also won the first prize of the China News Awards. Another example is the "Time Museum" theme activity launched by People's Daily, H5 Look! This is My Photo in Military Uniform, the finger dance relay challenge in "China Is Very Admired", etc., all of which made the audience enthusiastic about participation through mobilizing the audience's multiple senses. There are many such cases. It is foreseeable that in the future, individual user's 
sensory system will continue to be developed to obtain more realistic and rich scene experience.

\section{Innovation of News Dissemination Channels}

In the era of media convergence, as the user relationship in the media system is characterized by "decentralization", emotional connection has become the internal logic of news communication channels. Furthermore, when news reports show users the meaning of news, they also consider how to convey the emotion, attitude and spiritual connotation behind the news.

\subsection{An Open Dialogue Relationship of Mobile Live Broadcast Establishing}

Dialogue not only enables the two parties to reach consensus on certain points of view, but also helps both parties find a new ideological basis that they agree with. Mobile live broadcast is the evolution of the development of network communication. The communicator can make the connection between people more deeply and directly by means of video and visualization. At present, in China, both traditional mainstream media and online media are rapidly gaining advantages in the field of mobile live broadcasting, and they have launched their own live broadcasting platforms, such as "CCTV News Mobile Network", "People Live" and "Live Cloud". Users can interact in real time through comments and barrage, and can even participate in the process of broadcast live with their own mobile phones and become content receivers and producers. The event platform built by mobile live broadcast breaks the closed loop of news release and news dissemination, allowing users to experience a sense of presence through dialogue with reporters. During the COVID-19, China Central Television's slow live broadcast of "Fire God Mountain"-hospital and "Thunder God Mountain"-hospital brought a sense of companionship and social interaction to the audience, which not only allowed 100 million people to participate in the "cloud supervision", but also eased people's anxiety. In the public domain constituted by mobile live streaming chat rooms, Chinese mainstream media are constantly improving their ability to integrate and innovate communication and to innovate ways of discourse. The public gained emotional recognition in the online gathering of mobile live streaming chat rooms and group resonance. Now, the media can use the form of mobile live broadcast to build a more diversified dialogue "situation" with the public, interpret, negotiate and even argue about the meaning of news according to the audience's position and receiving habits, so as to achieve the purpose of information sharing and emotional interaction (Zheng et al., 2020).

\subsection{Platform Transformation Meets Personalized Communication Relationship}

In the new medium's environment, the communication boundary between Chinese traditional media and online media is gradually blurred. Many content re- 
sources are homogenized and vulgar, causing audience fatigue and lack of choices. Therefore, in the process of integration of new media and traditional media, content resources should be optimally configured in their own channel applications to meet the individual needs of the audience. For example, New Media controls content resources based on big data analysis, reduces the cost of information acquisition, and enables the best allocation of resources. China's traditional media is committed to creating its own specialized platform, screening, sorting and improving the quality of information resources, while expanding its media business to other areas to better achieve cross-border cooperation. Relying on the advantages of traditional media in content production, gradually establish one-way, two-way, interactive and other forms of communication with the audience to complete the platform extension and transformation in the era of media convergence. For example, Chinese "Beijing News" launched "We Video" in 2016, while retaining its original newspaper business, taking the lead in proposing mobile communication and video expression first. In 2018, the Beijing News began to build the mobile clients as the main communication position, launched the "Beijing News APP", and launched "news + business" (+government affairs, +people's livelihood, +services), etc. in due course. While strengthening the pattern of "newspaper, internet, terminal, and micro", the Douyin account and Kuaishou account were opened. As of October 2020, the Beijing News has reached 43.47 million Weibo fans, 13 million video fans, and 7 million Beijing News Shell Finance fans. Through the transformation, the Beijing News has not only opened up communication channels in all fields, but also built a comprehensive communication relationship with the audience. The Beijing News is a microcosm of the transformation of traditional Chinese media platforms.

Although the development and application of communication technology has brought a unique and brand-new news experience to Chinese audiences, the emergence of technology is still affected by a deeper social context. Through many complicated forms of dissemination, it can be found that the nature of the change in the form of information dissemination is actually a change in the communication relationship.

\section{Summary}

The practice of the Chinese media reconstructing the relationship between the audiences has proved that new media technology provides a wealth of means and possibilities for the construction of the relationship between the media and the audience, and there is still a lot of space to be exploited. For Chinese journalism, realizing digital transformation from a relational perspective will become a dynamic and continuous process. Specifically, in the era of integrated media, traditional media must actively integrate into the open Internet platform on the one hand, and build an efficient media platform with its own advantages in specialization and content production; on the other hand, making full use of Internet new media technology, it needs to provide a more effective emotional inte- 
raction mode, to respect the main status of the audience, to render the audience with high-quality news reports with service thinking and product thinking, to allow the audience to actively participate in the process of news production and dissemination, and to maximize the information connection and emotional interaction with users, realizing the reconstruction of the relationship between the media and the audience.

\section{Conflicts of Interest}

The author declares no conflicts of interest regarding the publication of this paper.

\section{References}

He, Z. C. (2020). A Narrative Analysis of "Integrated Reporting" in the Context of New Media: The Case Study of the Winning Works of the 29th China News Awards Media Integration Award. View on Publishing.

Li, B. S. (2020). Anchors Talking News: News Reproduction in the Context of Media Convergence. TV Research, 2, 65-68.

Qi, A. J. et al. (2020). Research on Narrative Fusion of Production of Intelligent Media News. Journal of Chongqing University (Social Science), 9, 122-128.

Tian, W. G., \& Zhang, S. C. (2017). From Information Cognition to Emotional Experience: Innovation of News Expression in the Age of Media. TV Research, 5, 7-10.

Zheng, R. H. et al. (2020). The Innovation of the Interaction Mechanism of the "Media-Public" in Public Opinion Field: Based on the observation of the Slow Live Streaming Broadcast of "Fire God Mountain"-Hospital and "Thunder God Mountain"-Hospital. Wechat Offical Account-Media Review, 10. 